\title{
THE EFFECT OF FILLER CONTENT AND STORAGE CONDITIONS ON LINEAR DIMENSIONAL CHANGE AND ACCURACY OF THE EXPERIMENTAL PRISMA AP.H COMPOSITE INLAY MATERIAL.
}

Razak AAA, Harrison A, Alani AH. The effect of filler content and storage conditions on linear dimensional change and accuracy of the experimental prisma AP.H composite inlay material. Annal Dent Univ Malaya 1996; 3: 11-17.

\begin{abstract}
The effect of filler content and storage conditions such as drying, storing in water and thermal cycling on linear dimensional changes were investigated and evaluated. The dimensional accuracy studies were performed using a specific designed mould and a coordinate measuring machine. The findings gave support to the view that filler content is an important factor influencing the physical and mechanical properties of the composite inlay material. The higher filler content gave less polymerization shrinkage. The greatest linear shrinkage recorded was $0.79 \%$. The average linear shrinkage (in air, water and thermal cycling) for $79 \%$ filler Prisma AP.H was $0.33 \%$, for $65 \%$ filler Prisma AP.H was $0.35 \%$ and for $50 \%$ filler Prisma AP.H was $0.42 \%$. Generally, dimensional changes was greatest when stored dry. This was followed by materials which were thermal cycled. The least dimensional change recorded was when the materials were stored in water.
\end{abstract}

* Abdul Aziz Abdul Razak BDS, MSc, PhD. Alan Harrison TD, BDS, PhD, FDSRCS. \# Adil Hamed Alani BDS, HDD, PhD.

Department of Conservative Dentistry Faculty of Dentistry, University of Malaya, 50603 Kuala Lumpur, Malaysia.

\# Department of Oral and Dental Science Bristol Dental School \& Hospital Lower Maudlin Street, Bristol, BS1 2LY, United Kingdom

* corresponding author

Key Words: Dimensional accuracy, filler content, storage conditions.

\section{INTRODUCTION}

Dimensional accuracy of a composite inlay restoration can be considered as the degree of reproduction of the form of the restoration compared to the cavity preparation or that of the cast reproduced from the cavity preparation. The degree to which the dimensions of a material alter with time after polymerization is said to be a measure of its dimensional stability. All available commercial composites contract on polymerization. This is a direct function of the amount of inorganic components present in the system (1). This polymerization shrinkage creates stresses between the composite margins and the tooth cavity only if it is bonded. These stresses will strain the interfacial bond between the composite and the tooth, creating microgaps which can allow marginal leakage.

Composite resins are generally classified by the type of filler/fillers used since most use similar resin matrices. There has been a general concensus that when all other things are equal, the type of filler used in a composite resin most affects its clinical and handling properties (2).

Adding reinforcing filler to a resin matrix will serve two purposes: firstly, it modifies and usually improves the physical properties of the material such as rigidity, hardness, compressive strength and a lower value for the coefficient of thermal expansion (3); secondly, it reduces the polymerization contraction of the resultant composite if the filler occupies a significant proportion of the volume of the composite material. This is because these inorganic fillers do not undergo any contraction during the setting reaction.

The filler content of macrofilled composites is about 78 per cent by weight and 55 per cent by volume whereas the filler loading of the microfilled composite resins varies from $30-60$ per cent by weight (4). Although microfilled composite restorations can attain very smooth surfaces as compared to those macrofilled, the material has a number of disadvantages such as high coefficient of thermal expansion, polymerization shrinkage, water sorption, low tensile strength and is more liable to fatigue fracture (2).

The most recent advancement in filler distribution has been the blending of the intermediate size particles of macrofilled resin with that of pyrogenic silica producing composites called hybrids. Hybrids are actually macrofilled composites with the addition of a large amount (7-15 per cent) of microfillers, microfiller pellets or microfiller complexes. Pyrogenic silica has been added in order to reinforce the organic matrix and to reduce the difference in properties between the inorganic macrofillers and the unfilled organic matrix $(5,6)$. Most current conventional composites are considererd hybrids and have more than 80 per cent filler by weight or $60-70$ per cent by volume.

The purpose of this study was to assess the linear dimensional changes of the composite material in the form of a cone with respect to changes in filler content and storage conditions.

\section{MATERIALS AND METHOD}

For the present study, experimental Prisma AP. H (DeTrey / Dentsply, Germany) of 3 different filler content (50\%, $65 \%$, and $79 \%$ by weight) was used.

The dimensional accuracy of the material was measured using conical-shaped composite specimens made 
from a stainless steel (s/s) mould. The cone is shaped $10.0 \mathrm{~mm}$ in diameter and $8.0 \mathrm{~mm}$ in height. Two circular lines (grooves) were made in the s/s mould, the first one approximately $1.0 \mathrm{~mm}$ from the base and the other approximately $5 \mathrm{~mm}$ from the base. The composite material was inserted into the mould in increments of 2.5 $\mathrm{mm}$ thickness and light-cured for 40 s each time. Each specimen was then heat-cured in water at $100^{\circ} \mathrm{C}$ for 5 min (the optimum curing cycle).

Fifteen specimens were prepared for each group of filler content. Out of the fifteen specimens, five specimens were left dry in air and five other specimens were placed in distilled water. These 10 specimens were then stored in an oven and maintained at $37^{\circ} \mathrm{C}$ for 7 days. The five remaining specimens were thermal cycled at

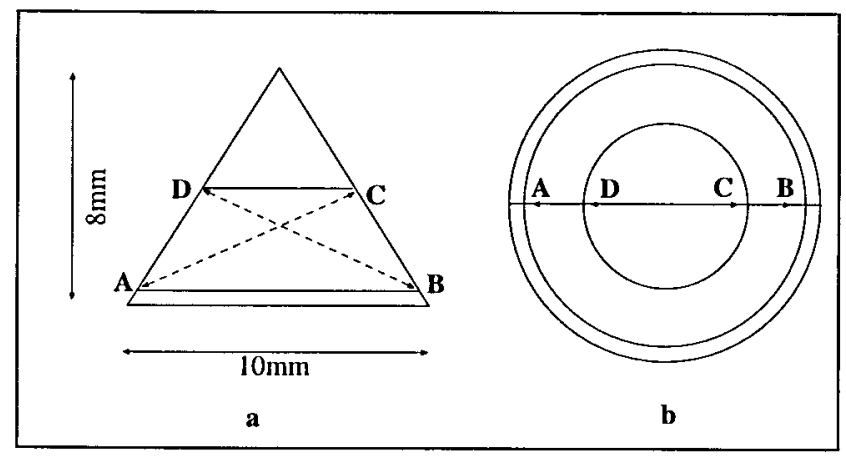

Figure 1 . Diagrammatic representation of the dimensions taken of the cone for measurements of dimensional accuracy ( $A B$, $\mathrm{CD}, \mathrm{AC}$ and $\mathrm{BD})$.

a - side view,

b - top view.

temperatures between $5^{\circ} \mathrm{C}$ and $60^{\circ} \mathrm{C}$ using a thermal cycling machine at $50 \mathrm{~s}$ immersion time and $5 \mathrm{~s}$ changeover time for 7 days. Forty-five specimens in total were prepared and tested in this study.

The dimensions of the composite cone and the $\mathrm{s} / \mathrm{s}$ mould were measured with a coordinate measuring machine (CMM) (Mitutoyo model BX 303, Mitutoyo UK., Andover England) fitted with a centering microscope of x50 maximum magnification. This was interfaced with a desktop computer (Vectra C5, Hewlett Packard, Berkshire, UK) running specialised software (Geopak Major, Mitutoyo UK Ltd., Andover, England). Measurements were taken of the four dimensions shown in Fig. 1, i.e. A to $B, C$ to $D, A$ to $C$ and $B$ to $D$. As the cone is symmetrical, there should be no significant difference between the two measurements $\mathrm{AC}$ and $\mathrm{BD}$. The results confirmed this and therefore the mean of the two readings was tabulated as the dimension :

$$
[(A C)+(B D)] / 2
$$

Repeated measurements were made of the position of the points A B, C D, A C, and B D and a statistical analysis of the results was carried out using the one-way analysis of variance and the Student's t-test. This apparatus, as stated by the manufacturer's calibration certificate has a resolution of $0.0005 \mathrm{~mm}$ and an accuracy of $0.001 \mathrm{~mm}(1 \mu \mathrm{m})$ with a measuring range of $300 \mathrm{~mm}$ in the $\mathrm{X}$ - and $\mathrm{Y}$ - axes. Measurements of dimensional accuracy using this apparatus have been described elsewhere (7).

Apparatus reliability (reproducibility) and operator variability were checked by measuring the dimensions of the s/s mould with the CMM. Measurements were made of the dimensions A B, C D, A C and B D on the sectioned $\mathrm{s} / \mathrm{s}$ mould. These measurements were repeated after 1 week followed by a statistical analysis of the results using the two-tailed $P$ values.

\section{RESULTS}

The mean values of dimensional change of the cones of different filler content measured at its base, at the mid-section and diagonally, after various storage condition are summarized in Table 1.

A one-way analysis of variance showed overall significant differences in the dimensional change between the groups. For dimension AB measurements, F (Snedecor's F Parameter) $=36.33$, df (degree of freedom), 8-36, $\mathrm{P}<0.001$, for dimension $\mathrm{CD}$ measurements, $\mathrm{F}=$ 36.91 , df, 8-36, $P<0.001$, and for dimension $[(A C)+(B D)] / 2$ measurements, $F=72.39$, df, $8-36, P<$ 0.001 .

The greatest dimensional change (shrinkage) recorded in this part of the study was $-71.98 \mu \mathrm{m}$ or $0.79 \%$ (for dimension $\mathrm{AB}$ ) for the material with $50 \%$ filler weight content stored dry in air for 7 days. The least change recorded was that of dimension $[(\mathrm{AC})+(\mathrm{BD})] / 2$ for the material with $65 \%$ filler weight content, after storing in water for 7 days which recorded a minimal $0.05 \%$ shrinkage.

Irrespective of storage conditions, whether dry, in water or thermal cycled, polymerization shrinkage was greatest at the base of the specimens (for all filler types) nearest to the light source, i.e. towards the exposed area.

The average linear shrinkage (in air, water and thermal cycling) calculated from Table 1 for the $79 \%$ filler Prisma AP.H was $0.33 \%$, for the $65 \%$ filler Prisma AP.H was $0.35 \%$ and for the $50 \%$ filler Prisma AP.H was $0.42 \%$.

Generally, for the composite cone the dimensional change for all the materials was greatest when stored dry. This was followed by materials which were thermal cycled. The least change recorded was when the materials were stored in water.

When left in the dry condition, there was a general tendency for polymerization shrinkage to increase with a decrease in filler content. However, when stored in water or when thermal cycled, linear shrinkage appeared to decrease with decrease in filler content for measurements near the external surfaces closer to the exposed areas (AB dimensions). Linear shrinkage measured at the midsection showed an increase with a decrease in filler content.

The reproducibility of measurements of the 
Table 1 A summary of the effect of storage condition and filler content on mean linear dimensional changes of experimental Prisma AP.H composite inlay cone after 7 days $(n=5)$.

\begin{tabular}{|c|c|c|c|c|c|c|}
\hline \multirow{2}{*}{$\begin{array}{l}\text { Storage } \\
\text { conditions }\end{array}$} & \multicolumn{6}{|c|}{ Dimensional changes $(\mu \mathrm{m})$} \\
\hline & A B & $(\%)$ & C D & $(\%)$ & {$[(\mathrm{AC})+(\mathrm{BD})] / 2$} & $(\%)$ \\
\hline $\begin{array}{l}79 \% \text { filler } \\
\text { Dry* } \\
\text { Water** } \\
\text { Thermal cycled*** }\end{array}$ & $\begin{array}{l}-59.20 \\
-58.10 \\
-70.22\end{array}$ & $\begin{array}{l}(0.65) \\
(0.63) \\
(0.76)\end{array}$ & $\begin{array}{r}-11.08 \\
-6.68 \\
-6.82\end{array}$ & $\begin{array}{l}(0.23) \\
(0.14) \\
(0.14)\end{array}$ & $\begin{array}{r}-15.54 \\
-6.32 \\
-6.04\end{array}$ & $\begin{array}{l}(0.20) \\
(0.08) \\
(0.08)\end{array}$ \\
\hline $\begin{array}{l}65 \% \text { filler } \\
\text { Dry* } \\
\text { Water** } \\
\text { Thermal cycled*** }\end{array}$ & $\begin{array}{l}-61.82 \\
-54.54 \\
-64.10\end{array}$ & $\begin{array}{l}(0.67) \\
(0.59) \\
(0.70)\end{array}$ & $\begin{array}{r}-19.40 \\
-8.56 \\
-11.76\end{array}$ & $\begin{array}{l}(0.40) \\
(0.18) \\
(0.24)\end{array}$ & $\begin{array}{r}-18.90 \\
-4.08 \\
-6.20\end{array}$ & $\begin{array}{l}(0.24) \\
(0.05) \\
(0.08)\end{array}$ \\
\hline $\begin{array}{l}50 \% \text { filler } \\
\text { Dry* } \\
\text { Water** } \\
\text { Thermal cycled*** }\end{array}$ & $\begin{array}{l}-71.98 \\
-37.98 \\
-46.50\end{array}$ & $\begin{array}{l}(0.79) \\
(0.41) \\
(0.51)\end{array}$ & $\begin{array}{l}-30.76 \\
-17.32 \\
-17.16\end{array}$ & $\begin{array}{l}(0.63) \\
(0.35) \\
(0.35)\end{array}$ & $\begin{array}{r}-40.72 \\
-12.36 \\
-7.46\end{array}$ & $\begin{array}{l}(0.51) \\
(0.16) \\
(0.09)\end{array}$ \\
\hline $\begin{array}{l}\text { original dimension } \\
\qquad(\mu \mathrm{m})\end{array}$ & 9159.70 & & 4908.00 & & 7921.30 & \\
\hline
\end{tabular}

-ve sign denotes shrinkage, $(\%)$ denotes negative percentage shrinkage.

${ }^{*}$ stored dry at $37^{\circ} \mathrm{C}$, ${ }^{* *}$ stored in distilled water at $37^{\circ} \mathrm{C}$, ${ }^{* * *}$ After thermal cycling between $5^{\circ} \mathrm{C}$ and $60^{\circ} \mathrm{C}$.

Calculated average linear shrinkage (dry, water, thermal cycled) for $79 \%$ filler Prisma AP.H was $0.33 \%$, for $65 \%$ filler Prisma AP.H was $0.35 \%$ and for $50 \%$ filler Prisma AP.H was $0.42 \%$.

Table 2 Reproducibility measurements of composite inlay cone mould (figures in mm., $n=5$ ).

\begin{tabular}{|l|l|l|l|l|c|}
\hline Dimension & & Time 1 & Time 2 & Difference & t \\
\hline & Mean & 9.1582 & 9.1612 & 0.0030 & \\
& S.D. & 0.0047 & 0.0048 & 0.0084 & 0.799 \\
& S.E. & 0.0021 & 0.0022 & 0.0038 & \\
\hline \multirow{2}{*}{$\mathrm{AD}$} & Mean & 4.9076 & 4.9078 & 0.0002 & \\
& S.D & 0.0059 & 0.0016 & 0.0047 & 0.095 \\
& S.E. & 0.0027 & 0.0007 & 0.0021 & \\
\hline \multirow{3}{*}[(\mathrm{AC})+(\mathrm{BD})]{$/ 2$} & Mean & 7.9212 & 7.9214 & 0.0002 & \\
& S.D. & 0.0004 & 0.0011 & 0.0015 & 0.298 \\
& S.E. & 0.0002 & 0.0005 & 0.0007 & \\
\hline
\end{tabular}

S.D. - standard deviation, S.E. - standard error mean, $\mathrm{t}=\mathrm{t}$-distribution.

Measurements at Time 2 were performed one week after Time 1. 
composite inlay cone mould taken one week apart was analysed in Table 2 using the two-tailed $P$ values. The results show that there was no significant difference $(\mathrm{P}>$ 0.05 ) between measurements of the inlay cone mould on different occasions. Since a high level of reproducibility was demonstrated, the measurement of the dimensions $A B$, $C D$ and $[(A C)+(B D)] / 2$ of the $s / s$ mould on both occasions was taken and averaged.

\section{DISCUSSION}

The degree to which the dimensions of a material alter with time after polymerizarion is said to be a measure of its dimensional stability. Craig (8) has stressed the importance of dimensional stability, together with water sorption and solubility, with regards to staining and leakage behaviour.

The degree of polymerization shrinkage of a composite depends on the molecular weight of the monomer, amount of monomer and amount of filler in the composite and the degree of conversion $(9,10)$. Various factors have a direct effect on polymerization shrinkage of a composite restorative material: size of restoration, cavity design, placement technique (incremental or bulk) and curing technique (chemical or light-curing) $(11,12)$.

General agreement exists about the concern over polymerization shrinkage which can lead to marginal discrepancy, but an acceptable quantitative measuring technique is still absent. Little attention has been given to the role of the size of the restoration. The magnitude of polymerization shrinkage is dependent on the size of the restoration as well as on the placement technique (13). It was recommended that a conservative cavity preparation with incremental placement be used when using composite resin as the restorative material. It has been reported that the vertical incremental technique was less effective than the diagonal incremental technique, reducing cuspal movement by more than $50 \%$ (14).

Some specimens were left dry, some wet and some thermal cycled during the study to determine the effect of hydration on dimensional change due to polymerization shrinkage. In the later stages, water sorption leading to expansion of the experimental Prisma AP.H composite material partly compensates for polymerization shrinkage.

The effect of polymerization shrinkage was observed in all different storage conditions - dry, wet or thermal cycled. The results showed that the degree of polymerization shrinkage that occurred in specimens stored dry was between 1.2 to 4.6 times more than those stored in water for at least 7 days. These findings could be attributed to the water sorption potential of composite resins. Storing the specimens in water for at least 7 days would allow some water sorption by the resin matrix and cause a subsequent expansion of the restoration. However, the hygroscopic expansion properties of composite resin alone should not be expected to relieve the initial stress created by polymerization of the inlay restoration. This study demonstrated that hygroscopic expansion was not sufficient to compensate fully for polymerization shrinkage which is in agreement with the finding of others (15). This expansion would not cause a perfect seal of a restoration but could at least contribute to less shrinkage.

Even if there was sufficient hydrophillic expansion taking place in certain composites, the process would require days or weeks to complete. Furthermore, water is involved in other degradatory processes which may make the hygroscopic expansion an undesirable solution to the contraction problem. It was found that the hygroscopic expansion of an anterior composite Silux (3M Co., St. Paul, U.S.A), closed the contraction gap, due to polymerization shrinkage, within 28 days (11). For the posterior composites however, the water sorption was found to be less and the hygroscopic expansion could not compensate for the shrinkage. This is in agreement with the present study. One reason put forward was that the posterior composites have a higher filler/matrix ratio than Silux $(16,17)$ and the reduced organic matrix will result in reduced water uptake (18). Very few restorative resins have hygroscopic expansion that can compensate fully for polymerization shrinkage $(11,19)$.

Thermal cycling does not significantly alter the magnitude or pattern of polymerization shrinkage of the composites in this study as compared to those specimens that were stored in water. This is similar to the finding of Derkson et al., (20) who found that thermal cycling does not alter the pattern of shrinkage in composite resin. Other studies however, have shown that thermal cycling significantly affected polymerization shrinkage when compared to storage at a constant temperature of $37^{\circ} \mathrm{C}$ $(21,22)$.

The applied thermal stress in thermal cycling may be considered severe since it provides an exposure of extreme temperatures which usually do not occur in the posterior region of the oral cavity (23). Thermal changes experienced on the surface of a tooth may only be $\pm 10^{\circ} \mathrm{C}$. Anything more than this is likely to cause pain. This therefore questions the value of thermal cycling in dimensional change studies. The results of studies which include long periods of extreme temperatures as part of their method, must therefore be interpreted with care. Thermal cycling which causes rapid dimensional changes may cause microcracking and degeneration of the surface layer. The effect of thermal cycling was not a summation of the effects caused at $5^{\circ} \mathrm{C}$ and $60^{\circ} \mathrm{C}$. As suggested by Mair (24), the cold phase of the cycle 'neutralized' the destructive effect of prolonged storage at high temperature. The main effect of cycling was to increase the depth of diffusion of water.

The mean linear shrinkage for the $79 \%, 65 \%$ and $50 \%$ filler experimental Prisma AP.H composite cone was $0.33 \%, 0.35 \%$ and $0.42 \%$ respectively. The correlation between filler content and shrinkage was $r=-0.958$ which was significant $(\mathrm{P}<0.01)$. From this result, it is shown that the increase in filler content decreases the 
polymerization shrinkage. Neither the polymerization shrinkage nor the hygroscopic expansion were uniform throughout the restorative material.

All composites including the macrofillers contract on polymerization depending on the amount of filler particles and type of resin used. The linear shrinkage is of the order of $0.5 \%-3.0 \%$. It was first thought that since microfiller composites have lower inorganic filler content, they would contract more than macrofilled composites on setting. On the contrary however, it was found that since most microfillers consist of prepolymerised resin particles in addition to the inorganic fillers, that this gives an overall loading similar to that of macrofilled composites (3). The contraction value will therefore be similar to that of macrofillers.

Polymerization shrinkage occurs in all resin systems because of the formation of a macromolecular chain network from monomer and prepolymer species. This involves the conversion of secondary intermolecular bonds (3-4 Angstrom distances) into primary covalent bonds of 1.5 Angstrom distances.

Several methods have been suggested in order to reduce polymerization shrinkage to almost nil and with some to even exhibit an expansion. Most of these are dependent on the formation of a second phase (liquid or gas) during the curing stage to counteract shrinkage of the resin $(25,26,27)$. This second phase however, tends to reduce the strength of the composite. Another method is by using cyclic or spiro-monomers that can expand on polymerization. This however, requires specific chemicals which are very expensive (28).

A particular composite system has been developed for the polymer concrete industry that does not change dimensionally during polymerization, by dispersing controlled amounts of the mineral montmorillonite (MMT) into the raw resin $(29,30,31)$. This system has high strength but the polymerization temperature can reach $140^{\circ} \mathrm{C}$. To reduce the temperature of polymerization to $60-80^{\circ} \mathrm{C}$, ammonia (NH3) was used to replace part of the hydration water in the system (32). When a $4 \%$ weight of ammonia-modified MMT was added to a Bis-GMA resin system with hydroxyapatite filler, no polymerization shrinkage was observed, compressive strength and hardness were comparable to other reported values for other composite resins and porosity was not detected (33).

Studies have shown that light-cured composite resin shrinks towards the polymerizing light source $(34,35)$. This is in agreement with the present study with the inlay cone where shrinkage was found to be greatest at the base of the specimens nearest to the light source.

Polymerization shrinkage in a composite resin inlay will therefore create a marginal gap between the cavity preparation and the restoration. However, this gap will be restored by the dual-curing composite cement interface. Polymerization shrinkage stress will also apply to this thin layer of composite. It was suggested that this dual-cure cement layer should not be thin since there will be a greater internal stress to break the cementation bond (36).

Use of the acid-etch technique has minimized leakage at enamel margins. However, in the absence of enamel margins such as in the cervical surfaces of the tooth, leakage continues to be a problem. Even with the use of a dentine bonding agent, it was revealed that their assessment of marginal leakage, as evidenced by dye penetration, showed leakage in more than $50 \%$ of the class $\mathrm{V}$ restorations (37).

A composite inlay restoration will always be subjected to a continuous cycle of compressive and tensile stresses as temperature in the oral cavity increases or decreases. These stresses may damage the adhesion between the inlay restoration and tooth and may even cause percolation to occur. One solution to the problem would be to develop a composite inlay material that has a coefficient of thermal expansion similar to that of the tooth and to have water sorption high enough to compensate the effect of polymerization shrinkage. The most desirable solution however would be to develop a composite material with very low polymerization shrinkage or one with no shrinkage at all. While resins that expand on polymerization have been researched (38), these have not been marketed.

Finally, since the difference in shrinkage of restorations in air and water was probably significant, it is recommended that indirect inlays made in the laboratory should be stored in water until ready for insertion in the clinic.

\section{CONCLUSION}

The conclusions that can be derived from this study are :

- For the composite inlay restorative in the shape of a cone, polymerization shrinkage was observed in all three storage conditions - dry, wet and thermal cycled.

- The hygroscopic expansion, however, observed in this part of the study was not sufficient to compensate fully for polymerization shrinkage.

- Thermal cycling did not significantly alter the magnitude or pattern of polymerization shrinkage of the experimental Prisma AP.H composite inlay material.

- There was an inverse linear relationship between filler content and polymerization shrinkage 


\section{REFERENCES}

1. Hosoda H, Yamada T and Inokoshi S. SEM and elemental analysis of composite resins. J Prosthet Dent 1990; 64 : 669-76.

2. Albers HF and Aso J. Direct composite restoratives. ADEPT Report 1991; 2(4):53-64.

3. McCabe JF. Resin-based filling materials. Applied Dental Materials. Blackwell Scientific Publications 1990; pp 145-56.

4. Craig RG. Chemistry, composition and properties of composite resins. Dent Clin North Am 1981; 25(2): 219-39.

5. Lutz F. Beitrage zur entwicklung von seitenzahnkomposits. 1st ed. Zurich, Kar Par PZM Verlag 1980; pp1-33.

6. Santucci EA and Racz WB. One year evaluation of posterior restorations in a primate model. J Dent Res 1982; 61 (Special issue A) Abstr. 618 pp. 247.

7. Harrison A., Huggett $R$ and Zissis A. Measurements of dimensional accuracy using linear and scanning profile techniques. Int J Prosthodont 1992; 5:68-72.

8. Craig RG. Mechanical properties and polymerization. Restorative Dental Materials. 8th Edition, Mosby. St. Louis, Missouri. 1989.

9. Ruyter IE. Monomer systems and polymerization. In: International Symposium on Posterior Composite Resin Dental Restorative Materials 1985; pp. 110.

10. Antonucci JM. Resin based dental composites - An overview. In : Polymers in medicine. Biomedical and pharmaceutical applications. Eds. Chiellini, E., Giusti, G. Migliaresi, C., Nicolai, L. New York: Plenum Press 1986; pp 277-303.

11. Hansen EK.. Visible light-cured composite resins: polymerization contraction, contraction pattern and hygroscopic expansion. Scand J Dent Res 1982; 90:329-35.

12. Feilzer AJ, de Gee $\mathrm{AJ}$ and Davidson $\mathrm{CL}$. Curing contraction of composites and glass-ionomer cements. J Prosthet Dent 1988; 59:297-300.

13. Council on Dental Materials, Instruments, and Equipment. Posterior composite resins. J Am Dent Assoc 1986; 112:707-9.

14. Jensen ME and Chan DCN. Polymerization shrinkage and microleakage. In: International Symposium on Posterior Composite Resin Dental Restorative Materials. Eds. Vanherle G and Smith DC. The Netherlands, Peter Szulc Publishing Co. 1985 pp. 243-62.

15. Bowen RL, Rapson JE and Dickson G. Hardening shrinkage and hygroscopic expansion of composite resins. J Dent Res 1982; 61:654-8.

16. Braem M, Finger W, Van Doren VE, Lambrechts $P$ and Vanherle G. Mechanical properties and filler fraction of dental composites. Dent Mater 1987; 5:346-9.

17. Ruyter IE and Oysaed H. Composites for use in posterior teeth: Composition and conversion. J Biomed Mater Res 1987; 21:11-23.

18. Braden M, Causton EE and Clarke RL. Water in composite filling materials. J Dent Res 1976; 5:730-2.

19. Asmussen $\mathrm{E}$ and Jorgensen $\mathrm{KD}$. A microscopic investigation of the adaptation of some plastic filling materials to dental cavity walls. Acta Odontol Scand 1972; 30:3-21.

20. Derkson GD, Pashley DH and Derkson ME. Microleakage measurement of selected restorative materials: A new in vitro method. J Prosthet Dent 1986; 56:435-40.

21. Crim GA and Mattingly SL. Evaluation of two methods for assessing marginal leakage. J Prosthet Dent 1981; 45:160-3.

22. Crim GA, Swartz ML and Phillips RW. Comparison of four thermocycling techniques. J Prosthet Dent 1985; 53:50-53.

23. Jager U. In vitro verschleiss festigkeitsmessinger an MOD-komposit fullungen nach kautkraft bezogenen schwelldruckbelastungen. Zahnmed Diss Zurich 1984.

24. Mair LH. Surface permeability and degradation of dental composites resulting from oral temperature changes. Dent Mater 1989; 5:247-55.

25. Skeist I. Epoxy resins. Reinhold, New York 1958; pp. 132-7.

26. Okada $\mathrm{T}$ and Konaka $\mathrm{T}$. Low shrinkage mechanisms in single-phase and two-phase unsaturated polyester resin mortar systems. In Proceeding, Third International Congress on Polymers in Concrete, Nihon University, Fukushima, Japan 1982: 1:447.

27. Czarnecki L. Expansive resin concrete. In Proceedings, Third International Congress on Polymers in Concrete, Nihon University, Fukushima, Japan 1982; 1:744.

28. Bailey WJ. Synthesis of monomers that expand on polymerization. J Elastoplastics 1977; 5:142-52.

29. Haque $\mathrm{E}$ and Armeniades CD. Montmorrilonite polymer concrete: Zero-shrinkage and expanding polymer concrete with enhanced strength. Polymer Engineering and Science 1986; 26(21):1524-30.

30. Haque $\mathrm{E}$ and Armeniades $\mathrm{CD}$. Interaction of Montmorillonite with resins to produce cure-expanding high-strength 
polymer concrete systems. Society of Plastics Engineer, technical papers 1986; 32:1296-7.

31. Haque E, Armeniades CD and Stormer J. Cure-shrinkage control with strength enhancement in polymer concrete by combining polymerization with mineral dehydration. In Staynes BW: The production, performance and potential of polymers in concrete. Brighton Polytechnic Press, Brighton, England 1987; pp. 182-92.

32. Liu CF and Armeniades CD. Cure shrinkage control of polymerization systems at ambient temperatures. Proceedings of the 47th Annual Conference of the Society of Plastic Engineers, Society of Plastic Engineers, New York 1989; pp. 834-7.

33. Liu CF, Collard SM and Armeniades CD. Constant-volume polymerization of composites by addition of ammoniamodified montmorillonite 1990; Am J Dent 3:44-50.

34. Hansen EK. Contraction pattern of composite resins in dentine cavities. Scand J Dent Res 1982 ; 90:480-3.

35. Bausch JR, de Lange K, Davidson CL., Peters A and de Gee AJ. Clinical significance of polymerization shrinkage of composite resins. J Prosthet Dent 1982; 48:59-67.

36. Feilzer AJ, de Gee AJ and Davidson CL. Increased wall-to-wall curing contraction in thin bonded resin layers. J Dent Res 1989; 68:48-50.

37. Fuks $A B$, Hirschfeld $Z$ and Grajower R. Marginal leakage of cervical resin restorations with a bonding agent. $J$ Prosthet Dent 1985; 54:654-7.

38. Stansbury JW. Synthesis and evaluàtion of new oxaspiro monomers for double ring-opening polymerization. J Dent Res 1992; 71:1408-12. 